\title{
Brainstem Bilirubin Toxicity in the Newborn Primate May Be Promoted and Reversed by Modulating $\mathrm{PCO}_{2}$
}

\author{
RICHARD P. WENNBERG, SIDNEY M. GOSPE, JR, WILLIAM D. RHINE, MASUD SEYAL,
} DIANE SAEED, AND GUSTAVO SOSA

\begin{abstract}
Division of Neonatology, Department of Pediatrics [R.P.W., D.S., G.S.]; Section of Child Neurology, Departments of Neurology and Pediatrics [S.M.G.]; and Department of Neurology [M.S.]. University of California, Davis, Davis, California 95616; Division of Neonatology, Department of Pediatrics, Stanford University, Stanford, California 94305 [W.D.R.]; and the California Primate Research Center, Davis, California 95616
\end{abstract}

\begin{abstract}
The auditory brainstem response (ABR) was monitored during infusion of bilirubin in six ventilated newborn rhesus monkeys (138-145 d gestation) while acute changes in $\mathrm{pH}$ were produced by varying inspired $\mathrm{CO}_{2}$. Prolonged respiratory acidosis without bilirubin infusion produced minimal changes in the ABR (one animal). $\mathrm{CO}_{2}$ exposure, usually initiated when the bilirubin level reached $\sim 20 \mathrm{mg} / \mathrm{dL}$, decreased arterial $\mathrm{pH}$ to values ranging from 6.85 to 7.10. ABR changes, including prolongation of the wave II-IV peak to peak intervals and decreased wave amplitudes, first developed $2-4 \mathrm{~h}$ after initial exposure to $\mathrm{CO}_{2}$. Total and unbound bilirubin levels at this time ranged from 376 to $564 \mu \mathrm{mol} / \mathrm{L}(22-33 \mathrm{mg} / \mathrm{dL})$ and 38 to $65 \mathrm{nmol} /$ L (2.5-3.8 $\mu \mathrm{g} / \mathrm{dL})$, respectively. Correction of respiratory acidosis produced partial to complete reversal of $A B R$ changes within 3 to $20 \mathrm{~min}$. Reexposure to $\mathrm{CO}_{2}$ immediately reproduced the $\mathrm{ABR}$ abnormality. Production and reversal of the abnormal ABR was obtained through two to three cycles in three animals. Thus, when the brainstem bilirubin level was near the threshold for toxicity, the effect of changes in $\mathrm{PCO}_{2}$ on the $\mathrm{ABR}$ were immediate, suggesting that auditory pathway toxicity is initially mediated by a reversible $\mathrm{pH}$-dependent bilirubin-membrane complex. In contrast to humans, in monkeys auditory toxicity appeared to be a late manifestation of bilirubin toxicity, inasmuch as all monkeys were obtunded and apneic 30-70 min before ABR abnormalities appeared. Notwithstanding these limitations, the results support the hypothesis that bilirubin toxicity can be both promoted and reversed by modulating brain pH. (Pediatr Res 34: 6-9, 1993)
\end{abstract}

Abbreviations

ABR, auditory brainstem evoked response

Bilirubin is a dicarboxylic acid and is thought to exist primarily as the dianion in plasma (1). The nearly insoluble free bilirubin acid concentration increases with decreasing $\mathrm{pH}$ and with increasing total bilirubin concentration, creating a supersaturated unbound bilirubin level in hyperbilirubinemic infants $(2,3)$. The uptake of bilirubin by tissue also increases with decreasing $\mathrm{pH}$ (4-9), whereas serum binding remains unchanged $(9,10)$, and

Received September 11, 1992; accepted February 10, 1993.

Correspondence: Richard P. Wennberg, M.D., Division of Neonatology, Department of Pediatrics TB 193, UC Davis, Davis, CA 95616.

Supported by Grants HD25241 and HD00891 from the National Institute of Child Health and Human Development.
Brodersen and coworkers (1-3) have proposed that bilirubin encephalopathy results from the deposition of insoluble bilirubin acid aggregates in or on susceptible neuronal membranes (1-3).

Although precipitation of bilirubin in membranes may represent the final stage of kernicterus (11), there is increasing evidence that early bilirubin toxicity and possibly the chain of events leading to lethal toxicity may be initiated by quite a different mechanism. It is unlikely that precipitation of a supersaturated bilirubin solution is responsible for changes in the ABR (12-18), because ABR abnormalities may be corrected during exchange transfusion even when the free bilirubin concentration remains above proposed levels of solubility $(2,12,13)$. Furthermore, we have found that nearly all binding of bilirubin to red blood cells or mitochondria is due to a reversible $\mathrm{pH}$-dependent mechanism involving a single proton addition (4). This suggested to us that the soluble monovalent anion and not the insoluble bilirubin acid is responsible for initial partitioning between plasma and tissue.

These observations led us to postulate that early toxicity might involve reversible $\mathrm{pH}$-dependent bilirubin-membrane complexes. If true, dissolution as well as formation of toxic complexes in brain should occur rapidly after a sudden change in brain $\mathrm{pH}$ and should be reflected in a measurable expression of neurotoxicity. To test this hypothesis, we examined the effects of $\mathrm{pH}$ jumps on brainstem function as measured by the ABR of jaundiced premature primates. We modified $\mathrm{pH}$ by $\mathrm{CO}_{2}$ inhalation because $\mathrm{CO}_{2}$ equilibrates rapidly across the blood-brain barrier, immediately altering cerebral $\mathrm{pH}$. The premature newborn rhesus monkey was selected as an experimental model because it is born with an immature bilirubin processing system resulting in unconjugated hyperbilirubinemia (19) and has a threshold for developing bilirubin brainstem toxicity similar to that seen in human newborn infants (20).

\section{MATERIALS AND METHODS}

Six newborn rhesus monkeys (Macaca mulatta) were delivered by cesarean section at 138-145 d gestation. The monkeys were immediately intubated and stabilized using an Infant Star ventilator (Infrasonics Corp., San Diego, CA). Arterial lines were placed for sampling, blood pressure monitoring, and glucose infusion. Blood was replaced with heparinized placental blood and maternal blood. Venous lines were established in the inferior vena cava for bilirubin infusion. The animals were initially sedated with ketamine. Blood gases were modulated by infusing $\mathrm{CO}_{2}$ into the gas humidifier. Oxygen and compressed air were blended in an attempt to maintain normal arterial $\mathrm{PO}_{2}$ values.

Bilirubin (Sigma Chemical Co., St. Louis, MO) was dissolved in $0.1 \mathrm{~N} \mathrm{NaOH}$, and diluted with saline containing essentially 
fat-free human serum albumin (Sigma) to obtain a final bilirubin concentration of $1 \mathrm{mg} / \mathrm{mL}$ and a bilirubin:albumin molar ratio of 20:1. Bilirubin-albumin solutions were refreshed hourly, shielded from light, and infused through a $0.45-\mu \mathrm{m}$ Millipore filter.

$A B R$ recordings were made immediately after stabilizing the preparation and at $5-$ to $10-\mathrm{min}$ intervals throughout the study using a Nicolet Compact IV electro-diagnostic system (Nicolet Biomedical Instruments, Madison, WI). Subcutaneous needle recording electrodes were placed over each mastoid and at the vertex. A ground electrode was placed on the forehead. Earphones (Nicolet, TDH-39) were placed $1 \mathrm{~cm}$ from the ear and produced clicks at $75 \mathrm{~dB}$ intensity relative to threshold in a group of adult humans with normal hearing. Masking noise of $45 \mathrm{~dB}$ intensity was given to the opposite ear. Responses to 2000 rarefaction click stimuli of $0.1 \mathrm{~ms}$ duration were averaged at a rate of $11.4 / \mathrm{s}$, stored on disk, and displayed on hard copy. The latencies and amplitudes from baseline of waves I, II, and IV were measured, and the I-IV and II-IV peak to peak intervals were calculated for each response (21-23). In the monkey, wave II arises from the cochlear nucleus and wave IV is generated by the lateral lemniscus (23); therefore, the II-IV peak to peak interval was used to measure brainstem conduction.

Total bilirubin levels were assayed by absorption at $460 \mathrm{~nm}$, correcting for $\mathrm{Hb}$. In five of six animals, unbound bilirubin levels were estimated using the peroxidase method (24) (UB Analyzer, Arrow Co., Osaka, Japan). Blood gases and electrolytes were monitored using a Nova Stat Profile 5 analyzer. Data were statistically analyzed using analysis of variance and paired $t$ test. This research was approved by the animal use committee of the University of California, Davis, and conformed to NIH guidelines for the care and use of laboratory animals.

\section{RESULTS}

Bilirubin was initially infused at a rate of $25 \mathrm{mg} / \mathrm{kg} / \mathrm{h}$, producing serum bilirubin levels ranging from 273 to $376 \mu \mathrm{mol} / \mathrm{L}$ (16$22 \mathrm{mg} / \mathrm{dL}$ ) by $1 \mathrm{~h}$. The infusion rate was then slowed and $\mathrm{CO}_{2}$ was introduced, raising the $\mathrm{PCO}_{2}$ to $12.4-16.7 \mathrm{kPa}(93-125 \mathrm{~mm}$ $\mathrm{Hg}$ ) and decreasing arterial blood $\mathrm{pH}$ to $6.85-7.10$. In one animal, $\mathrm{CO}_{2}$ was introduced $2.4 \mathrm{~h}$ before bilirubin infusion, producing a minimal $\mathrm{pH}$ of 6.89 . This produced minimal changes in the ABR: a slight increase in wave I latency ( 2.60 to $2.84 \mathrm{~ms})$ and an increase in wave IV amplitude (0.46 to 0.68 $\mu \mathrm{V})$.

Initially, the animals responded to the elevated $\mathrm{PCO}_{2}$ with tachypnea and agitation, requiring ketamine sedation. After exposure to hyperbilirubinemia and hypercarbia for $1.5-2 \mathrm{~h}$, the animals became depressed, with minimal response to stimulation and only reflex inspiration during positive pressure ventilation. Changes in the ABR first appeared 30-70 min after general neurologic depression was observed.

Maximum bilirubin levels during the procedure ranged from 410 to $564 \mu \mathrm{mol} / \mathrm{L}(24-33 \mathrm{mg} / \mathrm{dL})$ and usually coincided with the onset of neurologic depression. Bilirubin levels ranged from 376 to $530 \mu \mathrm{mol} / \mathrm{L}(22-31 \mathrm{mg} / \mathrm{dL})$ when $A B R$ changes first appeared. At this time, unbound bilirubin levels ranged between 38 and $65 \mathrm{nmol} / \mathrm{L}(2.2-3.8 \mu \mathrm{g} / \mathrm{dL})$. Serum binding deteriorated in most animals as signs of toxicity progressed, and the unbound bilirubin levels generally remained high despite a decrease in total serum bilirubin concentration.

ABR changes initially consisted of prolongation of II-IV interval, followed by a decrease in amplitude in waves II or IV. Wave I remained intact in five of six animals. When the amplitude in any wave form decreased $50 \%$ or more, $\mathrm{CO}_{2}$ infusion was discontinued and minute ventilation was increased. In all animals, there was immediate recovery in the ABR, with the ABR approaching baseline values within $10 \mathrm{~min}$ in three of six animals (Fig. 1, Table 1). Two monkeys had partial improvement and one animal had only transient improvement. The most

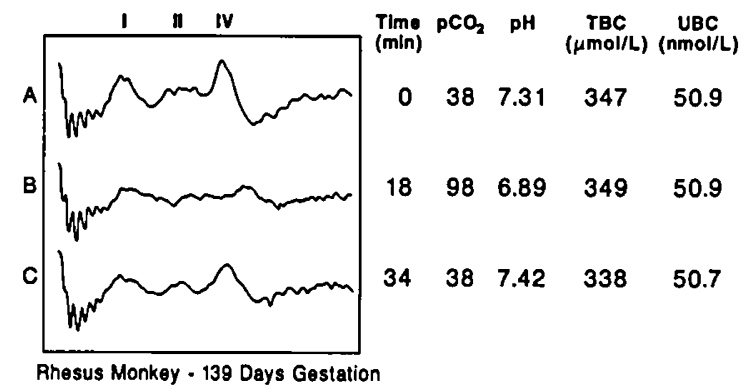

Fig. 1. Response of $A B R$ to hyperbilirubinemia and a second episode of hypercarbia in a 139-d gestation primate. $A$, ABR obtained 20 min after termination of initial $\mathrm{CO}_{2}$ exposure. Changes associated with initial hypercarbia (not shown) have reversed, and the ABR is nearly identical with the baseline $\mathrm{ABR}$ obtained before bilirubin infusion. $B, A B R 16$ min after reintroduction of $\mathrm{CO}_{2}$ into the ventilator circuit. $C$, Recovery of ABR $14 \mathrm{~min}$ after cessation of $\mathrm{CO}_{2}$ supplementation. $T B C$, total bilirubin concentration; $U B C$, unbound bilirubin concentration.

Table 1. Conditions of first ABR change and reversal

\begin{tabular}{|c|c|c|c|c|c|c|}
\hline & $\begin{array}{c}\text { II-IV } \\
\text { interval } \\
(\mathrm{ms})\end{array}$ & $\begin{array}{c}\text { Wave IV } \\
\text { amplitude } \\
(\mu \mathrm{V})\end{array}$ & $\begin{array}{c}\text { Blood } \\
\mathrm{pH}\end{array}$ & $\begin{array}{r}\mathrm{PCO}_{2} \\
(\mathrm{kPa}) \\
\end{array}$ & $\begin{array}{l}\text { Bilirubin } \\
(\mu \mathrm{mol} / \mathrm{L})\end{array}$ & $\begin{array}{c}\mathrm{UBC} \\
(\mathrm{nmol} / \mathrm{L})^{*}\end{array}$ \\
\hline \multicolumn{7}{|l|}{ Animal 1} \\
\hline Baseline & 2.02 & 0.59 & 7.42 & 7.5 & & \\
\hline lst change & 2.72 & 0.00 & 6.91 & 16.7 & 393 & \\
\hline Reversal & 1.98 & 0.25 & 6.97 & 10.7 & 393 & \\
\hline \multicolumn{7}{|l|}{ Animal $2 \dagger$} \\
\hline Baseline & 1.72 & 0.29 & 7.36 & 4.5 & 410 & 44 \\
\hline 1st change & 2.12 & 0.04 & 6.99 & 15.2 & 342 & 53 \\
\hline Reversal & 1.68 & 0.24 & 7.45 & 4.0 & 342 & 52 \\
\hline \multicolumn{7}{|l|}{ Animal 3} \\
\hline Baseline & 2.10 & 0.43 & 7.39 & 4.8 & & \\
\hline Ist change & 2.44 & 0.24 & 6.97 & 12.4 & 427 & 65 \\
\hline Reversal & 1.80 & 0.31 & 7.31 & 5.1 & 359 & 52 \\
\hline \multicolumn{7}{|l|}{ Animal 4} \\
\hline Baseline & 2.16 & 0.25 & 7.38 & 4.4 & & \\
\hline Ist change & 2.84 & 0.14 & 6.93 & 15.5 & 376 & 38 \\
\hline Reversal & 2.24 & 0.13 & 7.27 & 5.1 & 342 & 36 \\
\hline \multicolumn{7}{|l|}{ Animal 5} \\
\hline Baseline & 2.44 & 0.58 & 7.35 & 4.8 & & \\
\hline 1st change & 2.56 & 0.36 & 7.02 & 13.1 & 461 & 43 \\
\hline Reversal & 2.50 & 0.53 & 7.37 & 5.3 & 495 & 39 \\
\hline \multicolumn{7}{|l|}{ Animal 6} \\
\hline Baseline & 2.09 & 0.25 & 7.35 & 5.7 & & \\
\hline 1st change & 2.54 & 0.09 & 7.05 & 12.9 & 529 & 55 \\
\hline Reversal & 2.22 & 0.26 & 7.60 & 2.4 & 564 & 50 \\
\hline
\end{tabular}

* UBC, unbound bilirubin concentration.

$\dagger$ Represents 2 nd change. This monkey was exposed to $\mathrm{CO}_{2}$ for $2.4 \mathrm{~h}$ before adding bilirubin. Before $\mathrm{CO}_{2}$ exposure, II-IV interval was 2.20 $\mathrm{ms}$, and IV amplitude was $0.46 \mu \mathrm{V}$. Wave IV amplitude increased to 0.68 with $\mathrm{CO}_{2}$ exposure. When bilirubin reached $410 \mu \mathrm{mol} / \mathrm{L}$, IV amplitude decreased to $0.29 \mu \mathrm{V}$ and II-IV decreased to $1.96 \mathrm{~ms}$. Normalization of $\mathrm{pH}$ reduced II-IV further to $1.72 \mathrm{~ms}$, but IV amplitude remained unchanged. These values are used as baseline for this primate.

significant change in the $A B R$ in response to $\mathrm{pH}$ manipulation was in the II-IV peak to peak interval. Data from the first cycle in each of the six animals demonstrated that acidosis in the presence of hyperbilirubinemia prolonged the II-IV interval from $2.13 \pm 0.17 \mathrm{~ms}$ (mean $\pm \mathrm{SD}$ ) to $2.54 \pm 0.25 \mathrm{~ms}$. With a return to a less acidotic $\mathrm{pH}$, this interval recovered to $2.06 \pm$ $0.30 \mathrm{~ms}\left(p=0.008, F_{2,15}=6.71\right)$ (Table 2$)$. The data were also analyzed by paired $t$ test, because the large SD in baseline values might obscure changes when comparing group means. Significant differences between $\mathrm{CO}_{2}$ exposure and both baseline and recovery values were found in wave IV latency and both I-IV and II-IV peak to peak intervals. 
Table 2. Initial changes and reversal of $A B R$ latencies $( \pm S D)$ after introduction and removal of $\mathrm{CO}_{2}$ supplementation

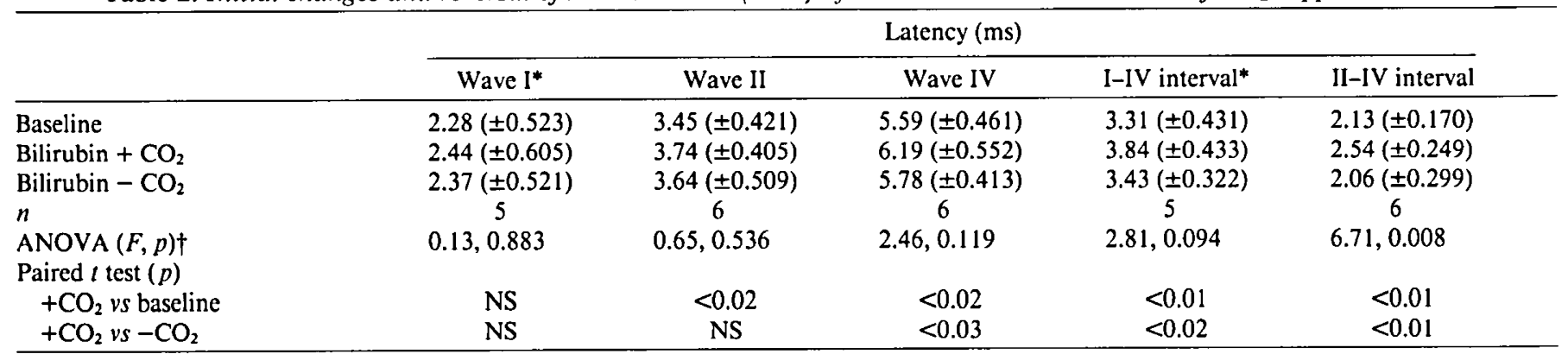

* Wave I not obtainable in one animal with bilirubin $+\mathrm{CO}_{2}$.

$\dagger$ ANOVA, analysis of variance.

Reinstatement of $\mathrm{CO}_{2}$ immediately reproduced the ABR abnormalities in all animals. Production and complete or partial reversal of the ABR abnormalities were obtained through two cycles in two animals and three cycles in one animal before irreversible clinical deterioration (hypotension, metabolic acidosis) occurred. The severity of $\mathrm{ABR}$ changes usually increased with each $\mathrm{CO}_{2}$ exposure.

Oxygen requirements increased during the procedure. In one animal, reversal of the $A B R$ abnormality occurred after increasing $\mathrm{pH}$ even with a $\mathrm{PO}_{2}$ value of $3.7 \mathrm{kPa}(28 \mathrm{~mm} \mathrm{Hg})$. Elevation of the $\mathrm{PCO}_{2}$ produced an increase in blood pressure and a decrease in heart rate in all animals. Conversely, normalization of the $\mathrm{PCO}_{2}$ resulted in a decrease in blood pressure. Three animals became hypotensive when the $\mathrm{PCO}_{2}$ was reduced (mean arterial pressure $16-22 \mathrm{~mm} \mathrm{Hg}$ ), but this did not prevent improvement in the ABR.

\section{DISCUSSION}

We report herein evidence that modulation of brain $\mathrm{PCO}_{2}$ and presumably brain $\mathrm{pH}$ acutely alters the threshold of bilirubin toxicity as measured by the ABR. When the tissue bilirubin level is near threshold for toxicity, the effect of changes in $\mathrm{PCO}_{2}$ on the ABR are immediate and dramatic, suggesting that auditory pathway toxicity is initially mediated by a reversible $\mathrm{pH}$-dependent bilirubin-membrane complex. The change in the II-IV peak to peak interval suggests that bilirubin primarily affects central conduction rather than the peripheral component of the $A B R$ (23). Wave I, reflecting peripheral 8th nerve function, was attenuated in only one animal.

Several studies have previously demonstrated that hypercapnia will increase brain bilirubin content (25-28), and this has been attributed to either alteration of $\mathrm{pH}$ or increased cerebral blood flow $(28,29)$. This study confirms previous suggestions that hypercarbia should increase bilirubin toxicity, but further demonstrates that reducing $\mathrm{PCO}_{2}$ can rapidly reverse bilirubin toxicity. This observation suggests that alteration of cerebral $\mathrm{pH}$ must play a more important role in the effect of hypercarbia on bilirubin toxicity, inasmuch as a decrease in cerebral blood flow with correction of hypercarbia would not be expected to rapidly remove bilirubin from brain. Although we hypothesized that increasing brain $\mathrm{pH}$ would reverse toxic bilirubin acid-membrane complexes, this study does not preclude the possibility that hypercarbia and bilirubin have independent but synergistic effects on brain function. In the absence of bilirubin, however, the $\mathrm{ABR}$ has been reported to be very resistant to hypoxic and hypercarbic conditions. Sohmer et al. (30) found a small but statistically significant increase in wave IV latency in cats under severe hypercarbic conditions $\left(25 \% \mathrm{CO}_{2}, \mathrm{pH} 6.8-6.9\right)$ but no effect on wave amplitude. Hypoxia had no effect on the ABR, although either hypoxia or hypercapnia severely depressed EEG activity. In this study, only one animal received prolonged exposure to $\mathrm{CO}_{2}$ with minimal changes in the $\mathrm{ABR} . \mathrm{CO}_{2}$ effects would be expected to occur fairly acutely, and all animals were exposed to $\mathrm{CO}_{2}$ for $2 \mathrm{~h}$ or longer in the presence of bilirubin before an effect was observed. Thereafter, changes were immediate. The delay in the onset of ABR changes is more likely due to the slow equilibration of bilirubin between plasma and brain compartments than to a delayed response to hypercarbia.

In contrast to humans, in the premature primate auditory toxicity appeared to be a late manifestation of bilirubin toxicity, at least under the experimental conditions used. All monkeys were obtunded and apneic before ABR abnormalities appeared. These manifestations of bilirubin poisoning were not reversed by eliminating respiratory acidosis and may or may not be mediated by a pH-dependent mechanism.

These studies are too preliminary to recommend the use of hyperventilation in treating patients with hyperbilirubinemia and signs of bilirubin encephalopathy, but they do emphasize the need to be attentive to brain $\mathrm{pH}$ and particularly to arterial $\mathrm{PCO}_{2}$ in patients at risk for kernicterus. Newborns with respiratory disease and hypercarbia associated with hyperbilirubinemia might be expected to have lower thresholds for neurotoxicity. These findings suggest that evaluation and treatment of patients with severe hyperbilirubinemia would be enhanced by measuring the arterial blood gas and monitoring acid-base status. This may be particularly important in patients undergoing exchange transfusion.

\section{REFERENCES}

1. Brodersen R 1979 Binding of bilirubin to albumin. CRC Crit Rev Clin Lab Sci 11:305-399

2. Eriksen E, Danielsen H, Brodersen R 1981 Bilirubin-liposome interaction. Binding of bilirubin dianion, protonization, and aggregation of bilirubin acid. J Biol Chem 256:4269-4274

3. Ebbesen F, Brodersen R 1982 Risk of bilirubin acid precipitation in pre-term infants with respiratory distress syndrome: considerations of blood/brain bilirubin transfer equilibrium. Early Hum Dev 6:341-355

4. Wennberg RP 1988 The importance of free bilirubin acid salt in bilirubin uptake by erythrocytes and mitochondria. Pediatr Res 23:443-447

5. Odell GB 1965 Influence of $\mathrm{pH}$ on distribution of bilirubin between albumin and mitochondria. Proc Soc Exp Biol Med 120:352-354

6. Silberberg DH, Johnson L, Ritter L 1970 Factors influencing toxicity of bilirubin in cerebellar tissue culture. J Pediatr 77:386-396

7. Bratlid $\mathrm{D} 1972$ The effect of $\mathrm{pH}$ on bilirubin binding by human erythrocytes. Scand J Clin Lab Invest 29:453-459

8. Katoh-Semba R, Kashiwamata S 1980 Interaction of bilirubin with brain capillaries and its toxicity. Biochim Biophys Acta 632:290-297

9. Nelson T, Jacobsen J, Wennberg RP 1974 Effect of pH on the interaction of bilirubin with albumin and tissue culture cells. Pediatr Res 8:963-967

10. Jacobsen J, Brodersen R 1976 The effect of $\mathrm{pH}$ on albumin-bilirubin binding. Birth Defects 12:175-178

11. Ahdab-Barmada M, Mossy J 1984 The neuropathology of kernicterus in the premature neonate: diagnostic problems. J Neuropathol Exp Neurol 43: $45-56$

12. Wennberg RP, Ahlfors CE, Bickers RG, McMurtry CA, Shetter JL 1982 Abnormal auditory brainstem response in a newborn infant with hyperbilirubinemia: improvement with exchange transfusion. J Pediatr 100:624-626

13. Nwaesei CG, Van Aerde J, Boyden M, Perlman M 1984 Changes in auditory brainstem responses in hyperbilirubinemic infants before and after exchange transfusion. Pediatrics 74:800-803

14. Perlman M, Fainmesser P, Sohmer H, Tamari H, Wax Y, Pevsmer B 1983 Auditory nerve-brainstem evoked responses in hyperbilirubinemic neonates. Pediatrics 72:658-664 
15. Lenhardt ML, McArtor R, Bryant B 1984 Effects of neonatal hyperbilirubinemia on the brainstem electric response. J Pediatr 104:281-284

16. Nakamura H, Takada S, Shimabuku R, Matsuo M, Matsuo T, Negishi H 1985 Auditory nerve and brainstem responses in newborn infants with hyperbilirubinemia. Pediatrics 75:703-708

17. Chisin R. Perlman M. Sohmer H 1979 Cochlear and brainstem responses in hearing loss following neonatal hyperbilirubinemia. Ann Otol Rhinol Otorhinolaryngol 89:352-357

18. Kaga K. Kitazumi E. Kodama K 1979 Auditory brainstem responses of kernicterus infants. Int J Pediatr Otorhinolaryngol 1:255-259

19. Gartner LM, Lee K. Vaisman S. Lane D. Zarafu I 1977 Development of bilirubin transport and metabolism in the newborn rhesus monkey. J Pediatr 90:513-531

20. Ahlfors CE, Bennett SH, Shoemaker CT, Ellis WG, Davis SL, Wennberg RP, Goetzman BW 1986 Changes in the auditory brainstem response associated with intravenous infusion of unconjugated bilirubin into infant rhesus monkeys. Pediatr Res 20:511-515

21. Allen AR, Starr A 1978 Auditory brain stem potentials in monkey (M. mulatta) and man. Electroencephalogr Clin Neurophysiol 45:53-63

22. Doyle WJ, Saad MM, Frea TJ 1983 Maturation of the auditory brain stem response in rhesus monkeys (Macaca mulatta). Electroencephalogr Clin Neurophysiol 56:210-223
23. Moller AR, Burgess J 1986 Neural generators of the brain-stem auditory evoked potentials (BAEPS) in the rhesus monkey. Electroencephalogr Clin Neurophysiol 65:361-372

24. Jacobsen J, Wennberg RP 1974 Determination of unbound bilirubin in the serum of newborns. Clin Chem 20:783-789

25. Diamond I, Schmid R 1966 Experimental bilirubin encephalopathy. The mode of entry of bilirubin $\cdot{ }^{14} \mathrm{C}$ into the central nervous system. J Clin Invest 45:678-689

26. Sawitsky A, Cheung WH, Seifter E 1968 The effect of $\mathrm{pH}$ on the distribution of bilirubin in peripheral blood, cerebrospinal fluid, and fat tissues. J Pediatr 72:700-707

27. Bratlid D, Cashore WJ, Oh W 1984 Effect of acidosis on bilirubin deposition in rat brain. Pediatrics 73:431-434

28. Burgess GH, Oh W, Bratlid D, Brubakk A-M, Cashore WJ, Stonestreet BS 1985 The effects of brain blood flow on brain bilirubin deposition in newborn piglets. Pediatr Res 19:691-696

29. Reivich M, Brann Jr AW, Shapiro H, Rawson J, Sano N 1971 Reactivity of cerebral vessels to $\mathrm{CO}_{2}$ in the newborn rhesus monkey. Eur Neurol 6:132136

30. Sohmer H, Gafni M, Chisin R 1982 Auditory nerve-brain stem potentials in man and cat under hypoxic and hypercapnic conditions. Electroencephalogr Clin Neurophysiol 53:506-512 